\title{
AVALIAÇÂO DO IMPACTO DA PRODUÇÃO DE AÇO COM BAIXO TEOR DE ENXOFRE NA VIDA REFRATÁRIA DAS PANELAS DE AÇO*
}

\author{
Ronaldo Adriano Alvarenga Borges ${ }^{1}$ \\ Guilherme Frederico Bernardo Lenz e Silva ${ }^{2}$
}

\section{Resumo}

A produção de aço com baixo teor de enxofre é de extrema importância para a indústria naval e de tubos para a indústria de petróleo. Porém, a fabricação destes aços acarreta um maior desgaste do revestimento refratário das panelas de transporte/tratamento de aço das aciarias devido às condições operacionais mais severas (maiores tempos de processo, maiores temperaturas, adições de fluxantes de escória, etc.) exigidas durante o processamento destes aços. Neste trabalho é apresentado o modelamento estatístico do impacto da fabricação deste tipo de aço, via rota de tratamento metalúrgico de dessulfuração de aço, na campanha refrataria (vida) das panelas conjuntamente com a análise post-mortem de tijolos refratários da linha de escória de uma das panelas. O modelamento levou em consideração os dados de 6 meses de operação da aciaria de uma usina integrada com capacidade de 4,5 Mt/ano. A análise dos resultados revelou que os altos tempos de tratamento no refino secundário, especialmente utilizando o forno panela como equipamento de dessulfuração, a adição de compostos fluxantes de escórias contendo sódio, como nefelina, são os principais fatores que degradam a vida do refratário de tais panelas. Palavras-chave: Refratários; Dessulfuração de aço; Desgaste de panela; Nefelina.

\section{EVALUATION OF STEEL PRODUCTION IMPACT WITH LOW SULPHUR LEVELS IN THE LIFE OF REFRACTORY OF LADLE STEEL TRANSPORT}

\section{Abstract}

Steel production with low sulfur content is extremely important for naval and industrial pipes to petroleum industry. However, the manufacture of these steels leads to increased wear of the refractory lining of steel ladle transport of the steelmaking because of the more severe operating conditions (increased process time, temperature, slag fluidizing additions, etc.) required during processing of such steels. This paper presents the statistical modeling of the impact of manufacturing this type of steel, via metallurgical treatment route of steel desulfurization in refractory campaign (life) of the ladles together with the post-mortem analysis of refractory bricks (slag line) of one this pots. The modeling took into account data from 6 months of operation of an integrated steelmaking plant with capacity of $4.5 \mathrm{Mt} /$ year. The results revealed that the high treatment times in the secondary refining, especially using the ladle furnace as desulphurization equipment, the addition of compounds containing sodium, such as nepheline, are the main factors that degrade the life of the refractory such ladles.

Keywords: Refractories; Steelmaking desulfurization; Ladle's wear; Nepheline.

1 Engenharia Metalúrgica, Engenheiro, Mestrando, Departamento de Metalurgia e Materiais, Universidade de São Paulo, São Paulo, SP, Brasil.

2 Engenharia Metalúrgica, Engenheiro, Professor Doutor, Departamento de Metalurgia e Materiais, Universidade de São Paulo, São Paulo, SP, Brasil. 


\section{INTRODUÇÃO}

Dentre os diversos tipos de materiais utilizados na indústria siderúrgica podemos destacar os materiais refratários, sendo estes muito utilizados como revestimento de equipamentos e vasos de transporte de gusa e aço nas aciarias de todo mundo. Aproximadamente $70 \%$ do consumo de materiais refratários vêm da indústria siderúrgica, o que na prática revela a importância destes materiais na composição de custos e na garantia de segurança operacional das usinas siderúrgicas [1]. Além disso, as frequentes paradas para manutenção de refratários interrompem as atividades operacionais concorrendo indiretamente para elevar os custos de produção do aço [1]. O uso intensivo de refratários nas usinas siderúrgicas é devido às propriedades que estes compostos apresentam como: elevada temperatura de início de fusão, resistência estrutural em altas temperaturas e em ambientes altamente corrosivos, estabilidade diante de variações térmicas intensivas, etc. Os gastos relativos ao consumo de refratários nos processos siderúrgicos representam uma parcela considerável dos custos de produção [2]. Estima-se que o consumo médio de refratários nos últimos anos no Brasil foi de 13,6 kg/t de aço, sendo que as aciarias consomem algo entre 5 e $15 \mathrm{~kg} / \mathrm{t}$, na sua maior parte nas panelas de transporte/tratamento do aço [2, 3, 4, 5].

Os principais mecanismos de desgaste de refratários seriam a corrosão química, hidratação, infiltração por aço e escória, erosão mecânica, desgaste e impacto mecânico, tensões termomecânicas, fadiga termomecânica [6]. Já os principais fatores que podem propiciar os mecanismos acima seriam o procedimento de préaquecimento, condições de injeção de gases, radiação de arco elétrico, práticas de manutenção de refratários, tempos de operação, temperatura de operação, design dos vasos, injeção de cálcio silício e processos de dessulfuração [6].

Este trabalho visa identificar o impacto que a fabricação de aço com baixo teor de enxofre (aços dessulfurados via rota/tratamento metalúrgico "Dessulfurado") traz para a vida do refratário das panelas de transporte de aço de uma aciaria.

O processo de desgaste de refratários tem como principal fator à corrosão química e, em alguns casos, é fortemente acelerado devido a danos em consequência das oscilações térmicas [1]. A corrosão química seria o processo inicial de degradação refratária sendo potencializada por posteriores tensões térmicas e mecânicas [7].

\section{MATERIAIS E MÉTODOS}

A partir dos dados dos sistemas de informações de produção (banco de dados operacionais), foram levantados os dados relativos à vida (campanha) das panelas, corrida a corrida, e variáveis operacionais como rota de tratamento metalúrgico de dessulfuração. O banco de dados foi relativo a seis meses de processo, compreendendo o período de 01/01/2014 a 30/06/2014. Este banco foi construído levando em consideração os dados de cada corrida processada nas panelas com o seu respectivo histórico das variáveis operacionais como, tempos de tratamento, tipo de aço, rota de tratamento, adições químicas, etc. Este período foi escolhido visando contemplar uma grande massa de dados (aproximadamente 6.700 corridas analisadas contemplando praticamente os dados de todas as panelas em operação deste período). Estes dados foram avaliados de forma a se remover erros como dados duplicados ou corridas com informações incompletas durante as campanhas. A partir daí foi analisado a influência da fabricação deste tipo de aço na vida das panelas através de correlações entre vida da panela e este tipo de tratamento 
metalúrgico via modelamento e regressão estatística. Em paralelo ao estudo estatístico, foram coletas amostras de refratário de uma das panelas de aço em operação após o final de sua campanha (amostras da linha de escória da panela), sendo preparadas e analisadas empregando microscopia óptica e eletrônica para realização da análise de post-mortem.

Neste trabalho foi possível identificar e inferir sobre alguns dos fenômenos e os possíveis mecanismos de desgaste que contribuem de maneira significante no desempenho em termos de vida do refratário das panelas. A Tabela 1 ilustra as principais características da composição do refratário das panelas de aço.

Tabela 1. Estrutura refratária das panelas de aço de acordo com as especificações técnicas

\begin{tabular}{cccccccc}
\hline \multicolumn{2}{c}{ Linha de Escória } & \multicolumn{2}{c}{ Linha de Metal } & \multicolumn{2}{c}{ Fundo } & \multicolumn{3}{c}{$\begin{array}{c}\text { Fundo (região de } \\
\text { impacto do jato) }\end{array}$} \\
\hline Composto & $(\%)$ & Composto & $(\%)$ & Composto & $(\%)$ & Composto & $(\%)$ \\
\hline $\mathrm{MgO}$ & 85 a 90 & $\mathrm{MgO}$ & 75 a 80 & $\mathrm{Al}_{2} \mathrm{O}_{3}$ & $\sim 79$ & $\mathrm{Al}_{2} \mathrm{O}_{3}$ & $\sim 88$ \\
\hline $\mathrm{C}$ & 11 a 13 & $\mathrm{Al}_{2} \mathrm{O}_{3}$ & 20 a 25 & $\mathrm{MgO}$ & $\sim 6$ & $\mathrm{C}$ & $\sim 6$ \\
\hline & & $\mathrm{C}$ & 5 a 8 & $\mathrm{C}+$ Outros & $\sim 15$ & $\mathrm{MgO}$ & $\sim 6$ \\
\hline
\end{tabular}

\section{RESULTADOS E DISCUSSÃO}

Para a análise da correlação entre a vida das panelas e a rota/tratamento metalúrgico que envolve a fabricação de aços com baixos teores de enxofre (enxofre $<0,006 \%$ e rota metalúrgica "Dessulfurado") foi realizado o agrupamento das rotas analisadas no período. Os 61 tipos possíveis de rotas metalúrgicas foram agrupados em 10 grupos, sendo o grupo Dessulfurado a rota de estudo em questão (Tabela 2).

Tabela 2. Grupos das rotas de tratamento metalúrgico analisados

\begin{tabular}{ccccc}
\hline Grupo & Descrição da Rota & Siglas & Corridas & $\%$ \\
\hline 1 & Ajuste de composição química & AJ CQ Sem CaSi & 1680 & 26,3 \\
\hline 2 & Ajuste de composição química & & & \\
\hline & com cálcio silício & AJ CQ Com CaSi & 217 & 3,4 \\
\hline 3 & Borbulhamento de argônio sem & Borb Arg Sem CaSi & 3013 & 47,1 \\
\hline 4 & cálcio silício & & & \\
\hline 5 & Borbulhamento de argônio com & Borb Arg Com CaSi & 65 & 1,0 \\
\hline 6 & Rota cálcio silício & CaSi & 90 & 1,4 \\
\hline 7 & Dessulfurado & Dessulfurado & 368 & $\mathbf{5 , 8}$ \\
\hline 8 & Desidrogenizado + Globulização & Desidrogenizado + & 126 & 2,0 \\
\hline 9 & Globulização com cálcio silício & Globulização CaSi & 792 & 12,4 \\
\hline 10 & Injeção de fio & Injeção de fio & 43 & 0,7 \\
\hline Total & & & $\mathbf{6 3 9 8}$ & $\mathbf{1 0 0}$ \\
\hline
\end{tabular}


A influência da participação percentual da rota dessulfurado na vida (campanha) das panelas pode ser vista na Figura 1. Esta rota engloba a sequência metalúrgica onde o aço é fabricado no conversor passando em seguida por refino no forno panela sendo posteriormente lingotada na máquina de lingotamento continuo. O que distingui esta rota das demais é a necessidade de dessulfuração do aço no forno panela (para níveis extremamente baixos de enxofre menores que $0,006 \%$ ) onde o revestimento refratário fica mais exposto ao arco elétrico, a tempos de processo de refino elevados e a adições de fluxantes de escória como a nefelina (composto altamente corrosivo e de alta capacidade de degradação refratária das panelas). Os resultados mostram que o aumento da participação \% de corridas cuja rota seja a de dessulfuração (rota Dessulfurado) em relação ao total de corridas durante a campanha da panela reduz a vida das panelas. Além disso, quando se faz a análise dos dados do bloco 1 (Figura 1) com os dados do bloco 2 (onde a referência é a mediana dos dados) verifica-se que houve um aumento de $16 \%$ na vida média das panelas com uma respectiva queda de $32 \%$ de participação média da rota de dessulfuração na campanha das panelas. Já a comparação do melhor desempenho (175 corridas com $5 \%$ de participação da rota dessulfurado) com o pior (92 corridas com participação de $11 \%$ da rota dessulfurado) revela uma diferença ainda maior (redução de $47 \%$ na vida média da panela).

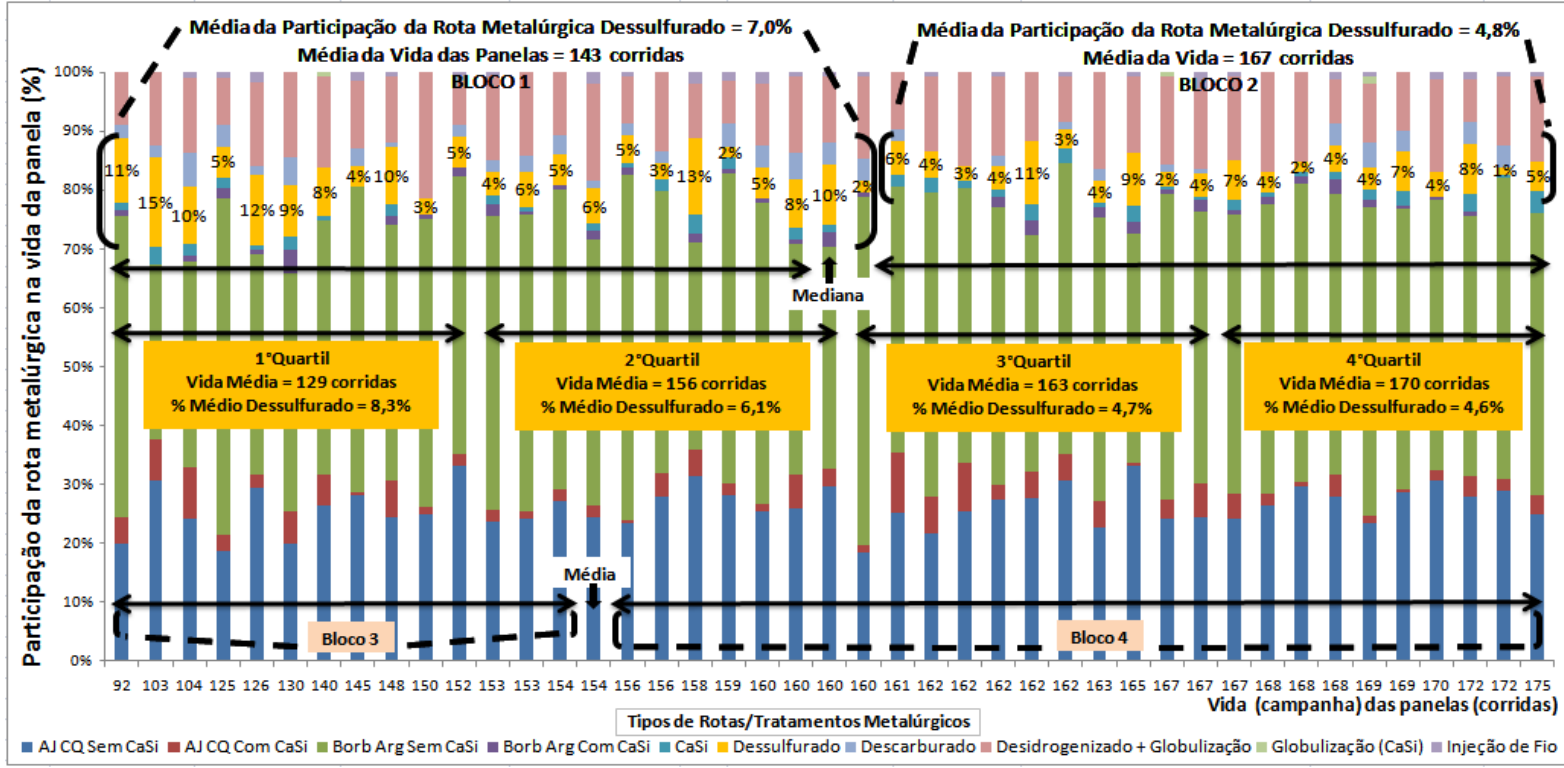

Figura 1. Influência da participação \% do grupo rota/tratamento metalúrgico Dessulfurado na vida das panelas.

Quando se considera a vida média das panelas (154 corridas) verifica-se que existe um aumento de $21,5 \%$ na expectativa de vida das panelas quando é comparado a vida média das panelas do bloco 3 (135 corridas) em relação ao bloco 4 (164 corridas) para uma redução de $31,9 \%$ no percentual de redução da participação da rota dessulfurado do bloco $3(7,5 \%)$ em relação ao bloco $4(5,1 \%)$. A análise por quartis revela, a princípio, uma redução da vida com aumento da porcentagem de rota dessulfurado entre todos os quartis. Porém, realizando uma análise de variância entre os quartis (teste $F$, sendo que para rejeição da hipótese nula de que as médias são iguais o $F$ observado deve ser maior que $F$ crítico ou a razão $F$ observado / $F$ crítico maior que 1) existe somente uma real queda da vida entre os quartis $3 \mathrm{em}$ relação a 1 e, entre o quartil 4 em relação ao 1 . As demais analises de variâncias (ANOVA) são indicadas nas Tabelas 3 e 4. 
Tabela 3. Análise de variância (ANOVA) para as comparações da vida média das panelas

\begin{tabular}{|c|c|c|c|c|c|c|}
\hline $\begin{array}{c}\text { Razão: } \\
\text { (F_observado / } \\
\text { F_crítico) }\end{array}$ & $\begin{array}{l}\text { Vida_1 }^{\circ} \\
\text { Quartil }\end{array}$ & $\begin{array}{l}\text { Vida_2 }^{\circ} \\
\text { Quartil }\end{array}$ & $\begin{array}{l}\text { Vida_3 } \\
\text { Quartil }\end{array}$ & $\begin{array}{c}\text { Vida_4 }^{\circ} \\
\text { Quartil }\end{array}$ & $\begin{array}{c}\text { Vida_ } \\
\text { Bloco } 2\end{array}$ & $\begin{array}{c}\text { Vida_ } \\
\text { Bloco } 4\end{array}$ \\
\hline Vida_1 ${ }^{\circ} Q$ uartil & 1 & 4,419 & 6,699 & 8,635 & NR & NR \\
\hline Vida_2 $^{\circ}$ Quartil & - & 1 & 7,497 & 28,497 & NR & NR \\
\hline Vida_3 ${ }^{\circ}$ Quartil & - & - & 1 & 9,585 & NR & NR \\
\hline Vida_4 ${ }^{\circ}$ Quartil & - & - & - & 1 & NR & NR \\
\hline Vida_Bloco 1 & NR & NR & NR & NR & 6,699 & NR \\
\hline Vida_Bloco 3 & NR & NR & NR & NR & NR & 9,111 \\
\hline
\end{tabular}

Símbolo (-) mesmo valor quando aij = aji, sendo aij o elemento da linha i e coluna j. Símbolo (NR) Não Realizado.

Tabela 4. Análise de variância (ANOVA) para as comparações do \% de rota Dessulfurado (\%DS)

\begin{tabular}{|c|c|c|c|c|c|c|}
\hline $\begin{array}{c}\text { Razão: } \\
\text { (F_observado / } \\
\text { F_crítico) }\end{array}$ & $\begin{array}{c}\% \text { DS_ } \\
1^{\circ} \text { Quartil }\end{array}$ & $\begin{array}{c}\% \text { DS_ } \\
2^{\circ} \text { Quartil }\end{array}$ & $\begin{array}{c}\% \text { DS_ } \\
3^{\circ} \text { Quartil }\end{array}$ & $\begin{array}{c}\% \text { DS_ } \\
4^{\circ} \text { Quartil }\end{array}$ & $\begin{array}{l}\% \text { DS_ } \\
\text { Bloco } 2\end{array}$ & $\begin{array}{c}\% \text { DS_ } \\
\text { Bloco } 4\end{array}$ \\
\hline$\%$ DS_1 ${ }^{\circ}$ Quartil & 1 & 0,498 & 1,471 & 1,691 & NR & NR \\
\hline$\%$ DS_2Q ${ }^{\circ}$ uartil & - & 1 & 0,265 & 0,355 & NR & NR \\
\hline$\%$ DS $3^{\circ}{ }^{Q}$ uartil & - & - & 1 & 0,004 & NR & NR \\
\hline$\%$ DS_4 ${ }^{\circ}$ Quartil & - & - & - & 1 & NR & NR \\
\hline$\%$ DS_Bloco 1 & NR & NR & NR & NR & 1,239 & NR \\
\hline \% DS_Bloco 3 & NR & NR & $\overline{N R}$ & NR & NR & 1,353 \\
\hline
\end{tabular}

Símbolo (-) mesmo valor quando aij = aji, sendo aij o elemento da linha i e coluna $j$. Símbolo (NR) Não Realizado.

A análise individual desta rota (dessulfurado) revela de maneira clara uma correlação negativa entre vida da panela e aumento da participação das corridas com rota dessulfurado na campanha refratária. A Figura 2 mostra o resultado da correlação estatística da vida versus participação desta rota na campanha.

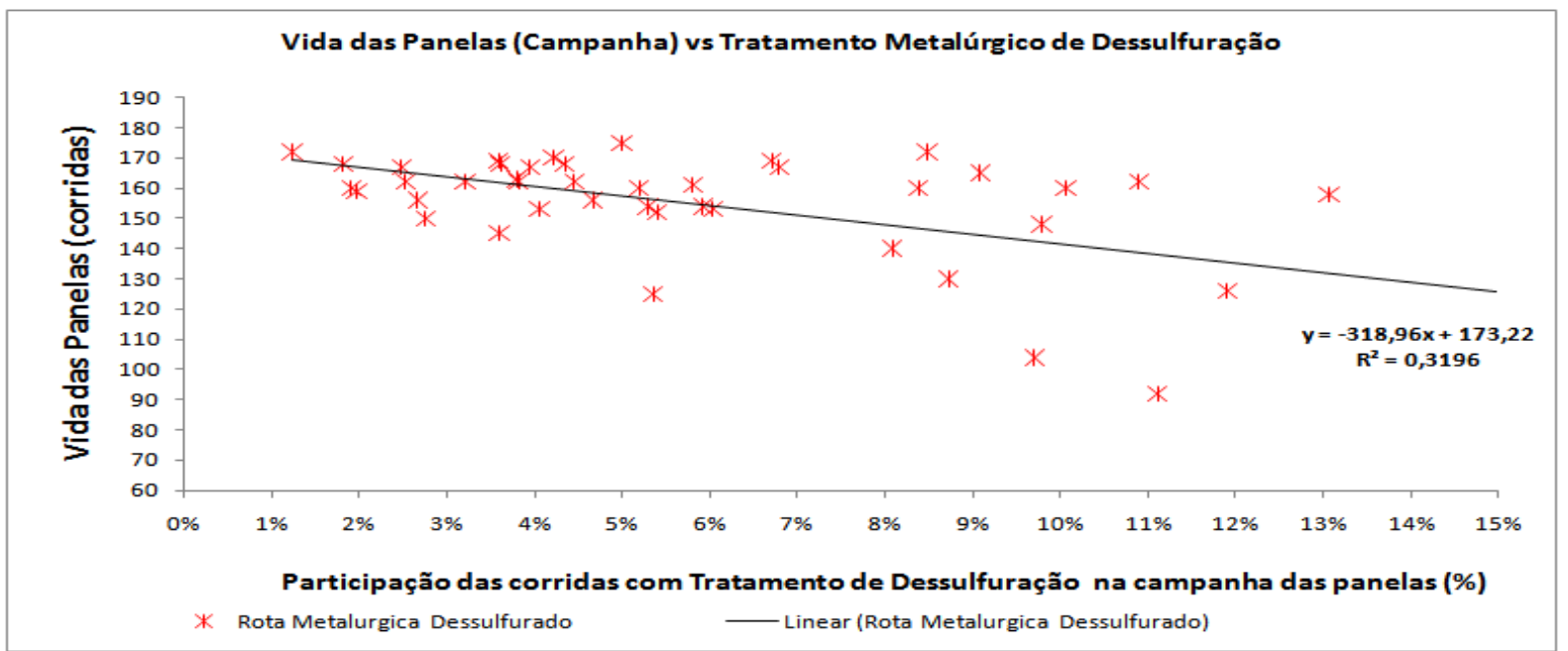

Figura 2. Correlação entre vida da panela de aço e a participação \% do grupo rota/tratamento metalúrgico Dessulfurado. 
Verifica-se que o aumento da participação, na campanha das panelas, de corridas que sofreram processo de dessulfuração impacta negativamente na vida refratária das panelas. Além das etapas básicas de ajuste de composição química e de temperatura, os processos que envolvem uma dessulfuração do aço para teores muito baixo de enxofre requerem altos tempos de processamento no refino secundário (no caso desta usina o forno panelas é o único equipamento do refino secundário capaz de realizar a dessulfuração), adições de fluxantes de escória como a nefelina e possíveis adições de fios de cálcio silício. Em média, o tempo de tratamento no refino secundário para este tipo de rota é $50 \%$ maior que uma rota comum. Outro fato relevante é que o uso do forno panela em processo de dessulfuração expõe mais acentuadamente o revestimento refratário das panelas ao arco elétrico dos eletrodos, o que na prática, degrada a estrutura refratária das panelas. Logo, para uma compreensão total do impacto, ou melhor, influência do tempo de contato do aço e escórias com o refratário das panelas, foi analisado o tempo de tratamento do aço nas estações de refino secundário (Power-On). Esta análise foi feita considerando, para cada panela, a vida em função dos tempos médios de tratamento para cada campanha.

A análise ratificou as análises anteriores e, mostrou o grande impacto, que aumento nos tempos de tratamento no refino secundário reduz a vida da panela consideravelmente. Nos casos analisados (19 panelas) 12 delas $(63,2 \%)$, apresentaram forte correlação negativa entre vida (campanha) e tempo de tratamento no refino secundário. Os gráficos das Figuras 3 e 4 ilustram as correlações negativas. Vale lembrar que o pequeno número de pontos nos gráficos nos dá uma falsa impressão de pequena amostragem, porém cada ponto representa uma campanha da panela, ou seja, cada ponto é na verdade uma média de 154 corridas com suas respectivas médias de tempo de tratamento no refino secundário.

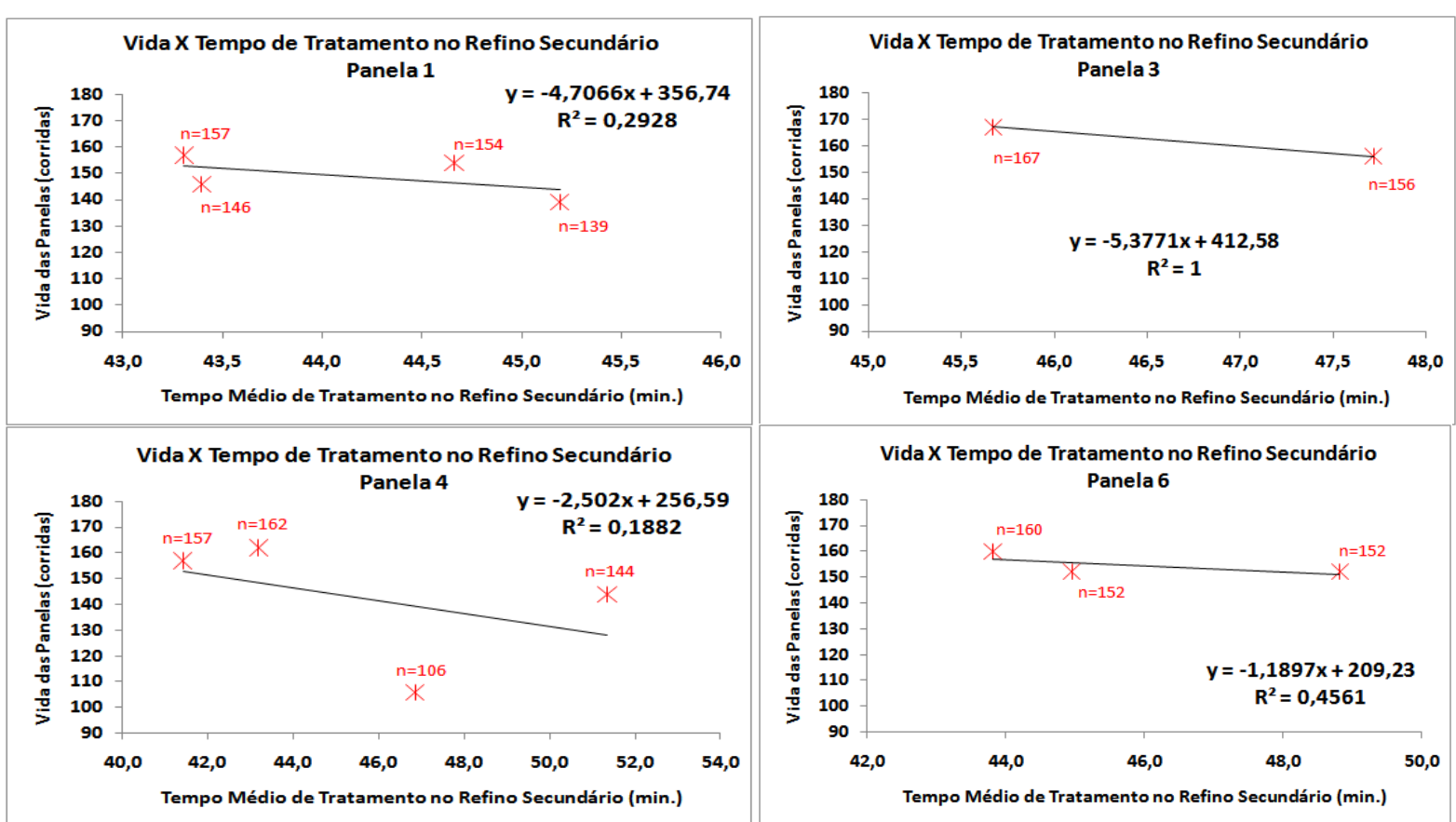

Figura 3. Correlação entre vida da panela de aço (campanha) e o tempo médio de tratamento no refino secundário das panelas $1,3,4,6$, onde $n$ é o número de corridas (Dados). 

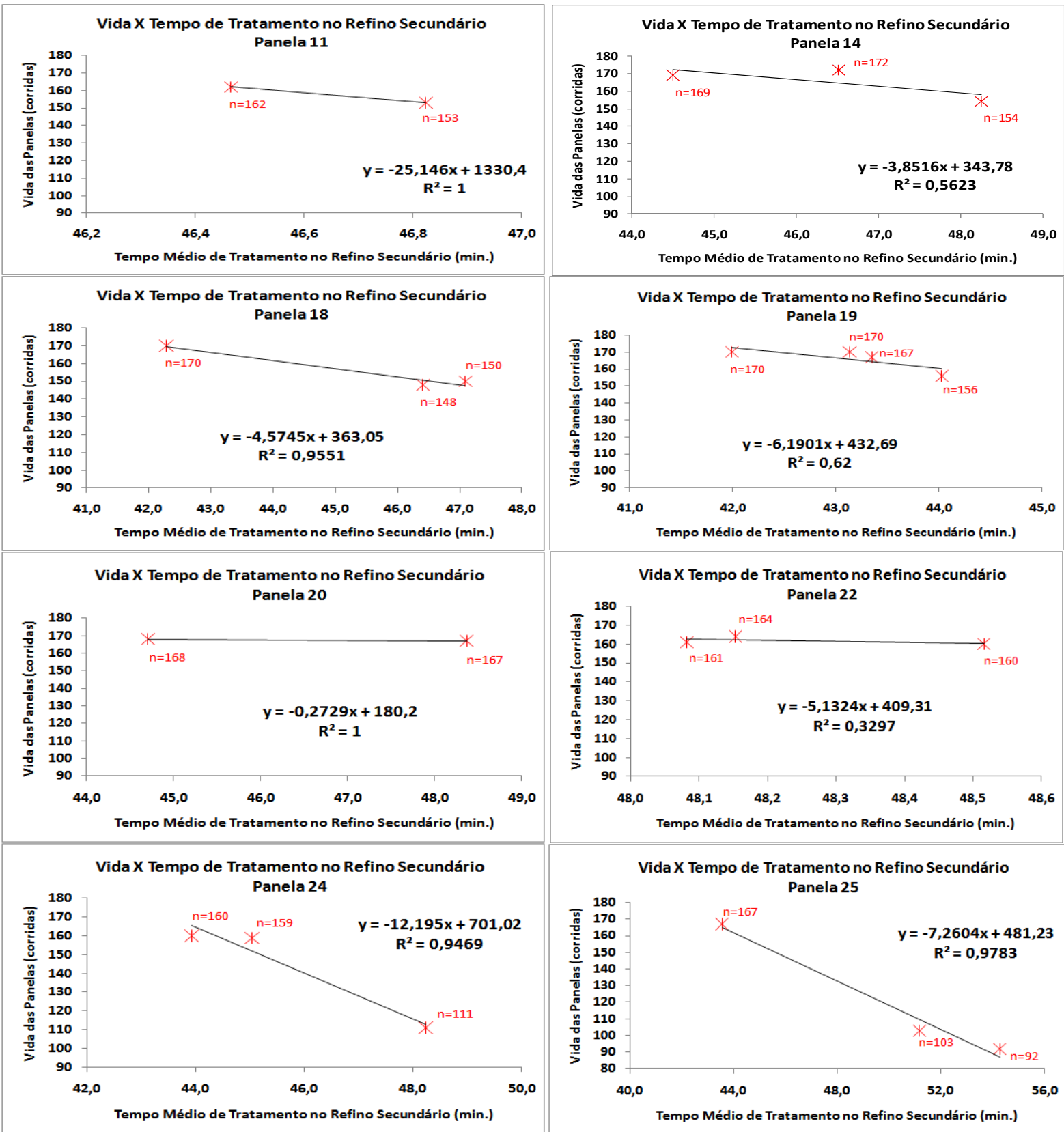

Figura 4. Correlação entre vida da panela de aço (campanha) e o tempo médio de tratamento no refino secundário das panelas $11,14,18,19,20,22,24$ e 25 , onde n é o número de corridas analisadas (Dados).

Considerando a queda na vida das panelas com o aumento do tempo de tratamento no refino secundário, nos casos acima, esta queda média foi de 4 corridas por minuto a mais de tempo de tratamento, isto é, para cada minuto a mais de tratamento do aço no refino secundário em relação ao tempo médio estima-se que a previsão da vida do refratário das panelas seja reduzida em 4 corridas. Esta queda representa, se considerarmos uma vida média das panelas de 154 corridas, redução de $2,6 \%$ na vida refratária por minuto a mais de tratamento no refino secundário em relação ao tempo médio de tratamento. A análise visual das Figuras 3 e 4 revela que as inclinações das curvas (coeficiente angular) são diferentes para cada panela, ou seja, a vida pode ser mais ou menos impactada dependendo de algum fator intrínseco (estrutura refratária) ou extrínseco (tipo de equipamento de refino secundário utilizado para tratamento do aço, por exemplo). Partindo da hipótese de 
que o revestimento refratário é semelhante entre as panelas (hipótese confirmada junto ao pessoal de manutenção refratária e fornecedores) e que o fator tipo de equipamento de refino secundário ao qual a panela será submetida ao longo de sua campanha é sempre citado na literatura e na área operacional como fator de grande relevância no desempenho das panelas, foi realizada uma análise para verificar a correlação entre o coeficiente angular (inclinação das curvas) e a participação percentual do tempo de tratamento de cada ajuste no refino secundário e o tempo total de tratamento metalúrgico. As análises confirmam as expectativas e mostram o impacto que o forno panela tem na degradação do refratário e consequentemente na vida das panelas. A Figura 5 ilustra o impacto negativo na vida das panelas quando a participação do forno panela é aumentada em detrimento do aumento dos demais equipamentos de refino (AHF, RH e EBA). Como pode ser visto na Figura 5, o único que possui inclinação negativa, ou seja, o aumento da participação do tempo total de tratamento deste refino diminui a expectativa de vida das panelas é o forno panela.

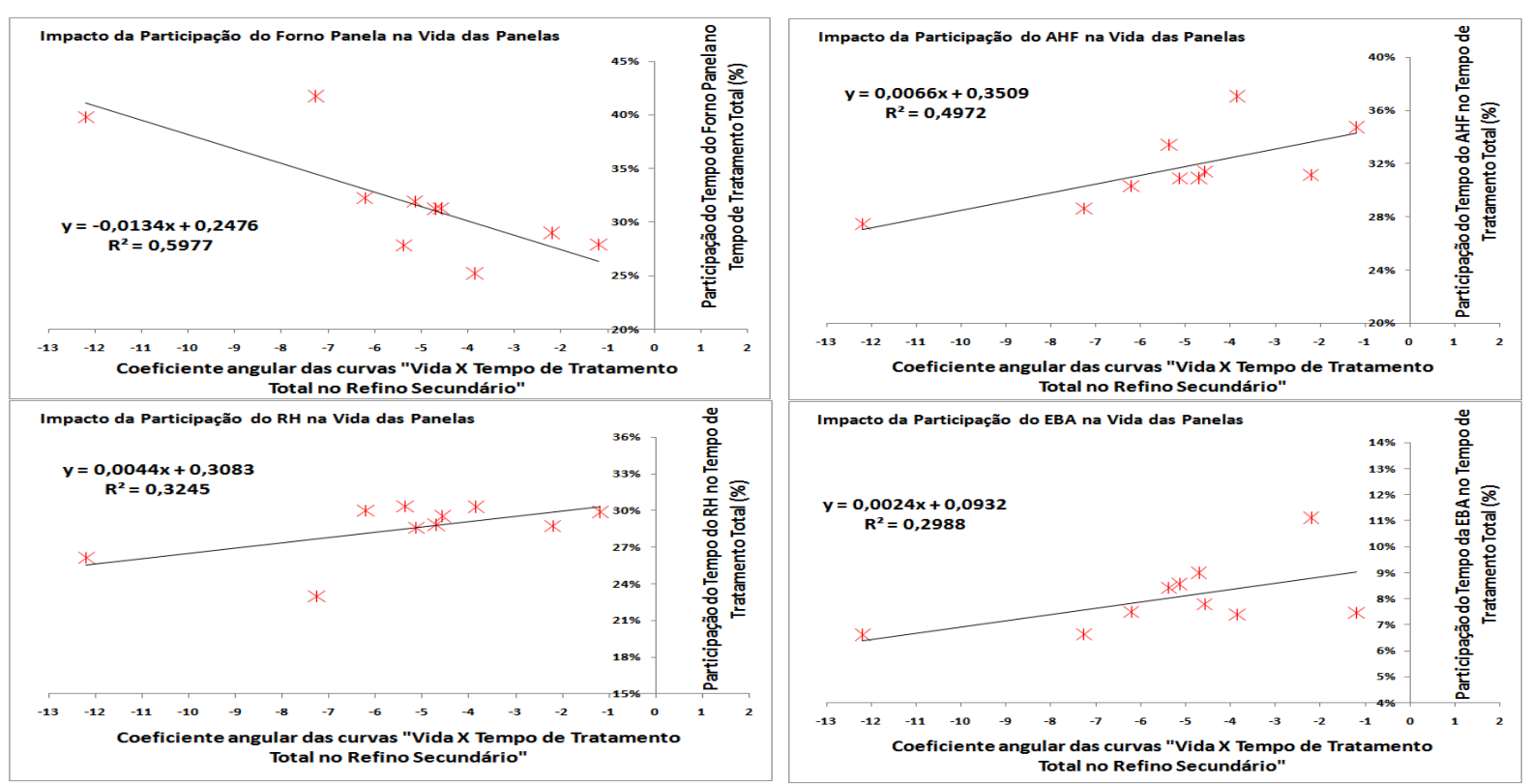

Figura 5. Impacto da utilização do Forno Panela, AHF, RH e da EBA na vida das panelas.

Cada ponto do gráfico apresenta a correlação de cada curva (coeficiente angular) com a participação percentual do tempo de tratamento em cada tipo de equipamento do refino secundário (forno panela, AHF, RH e EBA) com o tempo total da operação de refino. Nota-se (Figura 5) que o forno panela impacta negativamente (quanto maior participação \% no tempo de tratamento total mais negativo é o coeficiente angular) em detrimento aos demais equipamentos que possui suas correlações totalmente opostas. $O$ fator que mais difere o forno panela dos demais equipamentos ( $\mathrm{AHF}$ e $\mathrm{RH}$ ) é a forma de aquecimento que no forno panela é via arco elétrico e nos demais é via aquecimento aluminotérmico. A EBA é um equipamento que simplesmente faz algumas adições, homogeneização e sem aquecimentos. Outro fator relevante na análise desta rota de tratamento metalúrgico, além da utilização do forno panela e dos altos tempos de tratamento seria a utilização de fluxantes de escória como a nefelina, prática comum em algumas aciarias. Com o intuito de otimização do processo de dessulfuração para níveis baixos de enxofre no aço. A análise do consumo de nefelina (Tabela 5) para os diferentes grupos de aço comprovou as suposições acima e revelou, em termos de consumo específico por 
grupo de aço, os altos consumos para os grupos de aço onde se praticam altas taxas de dessulfuração (grupo baixo enxofre e duplo refino da Tabela 5).

Tabela 5. Consumo específico de nefelina por grupos de aço

\begin{tabular}{ccc}
\hline Grupo & Consumo Médio & Desvio em relação à média geral \\
\hline Alto Carbono & $0,49 \mathrm{~kg} / \mathrm{t}$. & $18,8 \%$ \\
\hline Baixo Enxofre & $\mathbf{1 , 1 4} \mathbf{~ k g} / \mathbf{t}$. & $\mathbf{1 7 7 , 6 \%}$ \\
\hline Comum & $0,15 \mathrm{~kg} / \mathrm{t}$ & $-63,6 \%$ \\
\hline Desgaseificado & $0,06 \mathrm{~kg} / \mathrm{t}$. & $-85,5 \%$ \\
\hline Duplo Refino & $\mathbf{1 , 0 6} \mathbf{~ k g} / \mathrm{t}$. & $\mathbf{1 5 8 , 4 \%}$ \\
\hline Peritético & $0,53 \mathbf{k g} / \mathrm{t}$ & $\mathbf{2 8 , 6 \%}$ \\
\hline UBC-Geral & $0,02 \mathrm{~kg} / \mathrm{t}$ & $-94,7 \%$ \\
\hline UBC-Usicore & - & - \\
\hline Média Geral & $\mathbf{0 , 4 1} \mathbf{~ k g / t .}$ & -
\end{tabular}

A análise post-mortem nos refratários da linha de escória de uma das panelas da aciaria (Figura 6 e Tabela 5) revelou os grãos da estrutura refratária de MgO-C sendo corroídos por uma escória de panela rica em sódio. Como a única adição química feita que contem este elemento é a nefelina conclui-se que este composto contribui de forma decisiva na degradação refratária das panelas.

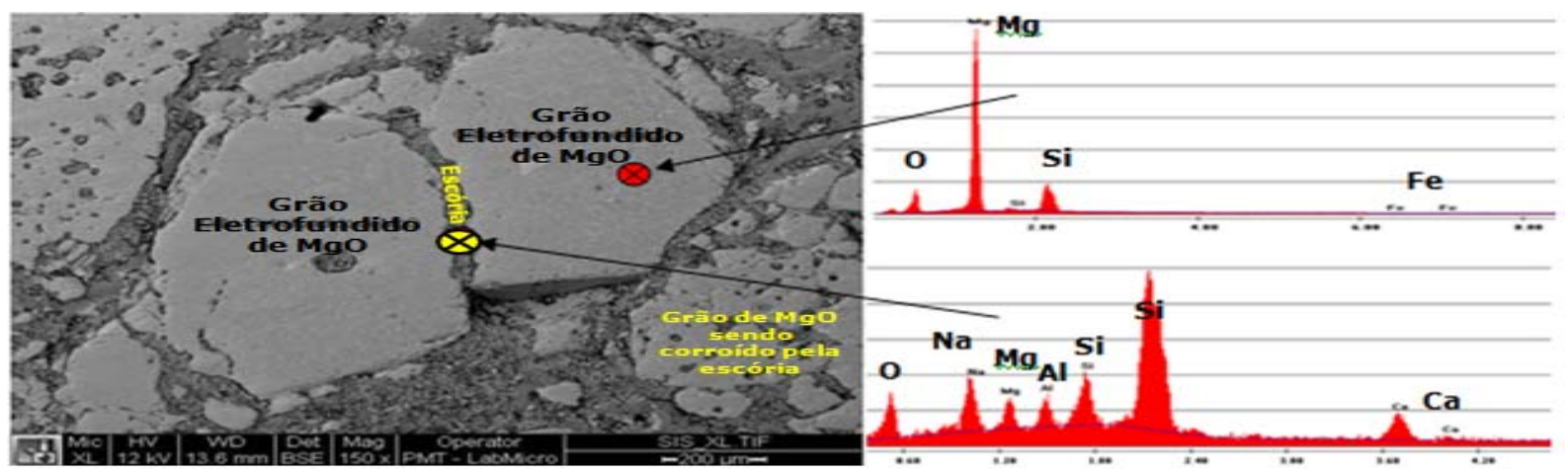

Figura 6. Imagem obtida (MEV) da região de interface (refratário/escória) do refratário das panelas. Grãos eletrofundidos de MgO (refratário) sendo corroídos pela escória infiltrada na matriz refratária.

Tabela 6. Análise química (MEV) dos grãos e da escória observados na região de interface. Escória rica em sódio, provavelmente nefelina. Análise semi-quantitativa (EDS)

\section{Composição Química dos Grãos de MgO Composição Química da Escória}

\begin{tabular}{cccc}
\hline Composto & $(\%)$ & Composto & $(\%)$ \\
\hline $\mathrm{MgO}$ & 95,04 & $\mathrm{Na}_{2} \mathrm{O}$ & 14,38 \\
\hline $\mathrm{SiO}_{2}$ & 1,70 & $\mathrm{MgO}$ & 12,27 \\
\hline $\mathrm{FeO}$ & 3,26 & $\mathrm{Al}_{2} \mathrm{O}_{3}$ & 13,99 \\
\hline \multirow{2}{*}{ Total } & \multirow{2}{*}{$\mathbf{1 0 0 , 0 0}$} & $\mathrm{SiO}_{2}$ & 31,21 \\
\cline { 2 - 4 } & & $\mathrm{CaO}$ & 28,16 \\
\cline { 2 - 4 } & & Total & $\mathbf{1 0 0 , 0 0}$ \\
\hline
\end{tabular}

A análise da região entre os grãos eletrofundindos de $\mathrm{MgO}$ (Figura 6) revela ser uma composição típica de escória (Tabela 6), o que comprova o exposto referente ao 
ataque pela escória na matriz e nos grãos de refratário. Este mecanismo de desgaste do refratário da linha de escória parece ser o fenômeno predominante nesta região. Os resultados das análises estatísticas entre vida refratária das panelas e rota de tratamento metalúrgica de dessulfuração de aços mostraram que o aumento da participação deste tipo de refino de aço degrada a estrutura refratária das panelas de forma intensa. Esta redução da vida das panelas está diretamente ligada aos altos tempos de tratamento do aço que esta rota metalúrgica exige nas estações de refino secundário, em especial, no forno panela que é o equipamento utilizado, na aciaria analisada, para realização de tais práticas. Os altos tempos estão ligados a altas taxas e período de aquecimentos via arco elétrico e adições de fluxantes de escória como a nefelina. A análise de post-mortem indica que o fenômeno de desgaste refratário preponderante sofrido por tais panelas é majoritariamente um desgaste ocasionado por corrosão química pela escória. Portanto, as práticas usuais de realizar o tratamento metalúrgico de dessulfuração dos aços para níveis baixos de enxofre que nesta usina incluem a dessulfuração com a utilização do forno panela (arco elétrico), altos tempos de processo (exposição a vários aquecimentos e adições) e a utilização de nefelina como agente fluxante são fatores decisivos para o desempenho das panelas de aço da aciaria.

\section{CONCLUSÃO}

Conclui-se que a rota de produção de aço dessulfurado, na qual se utiliza o forno panela para realização do refino secundário dos aços para baixo teor de enxofre, com adições de fluxantes como a nefelina e altos tempos de tratamento (Power on) reduz a expectativa de vida das panelas de aço na aciaria. Portanto, para um melhor desempenho da vida das panelas de transporte de aço é preciso racionalizar o uso do forno panela e da adição de fluxantes de escória que contém sódio.

\section{Agradecimentos}

Os autores agradecem à empresa pela disponibilização dos dados de processo.

\section{REFERÊNCIAS}

1 QUINTELA, M. A. Caracterização de cerâmicas refratárias para panela de aço. Brasil, Universidade Federal de São Carlos, Dissertação apresentada ao Programa de PósGraduação em Ciência e Engenharia de Materiais, 2003.

2 BRAGANÇA, S. R. Corrosão de refratários utilizados na siderurgia. Cerâmica 58, 2012, 280-285.

3 FERREIRA, J. P. Estudo dos desgastes de refratários dolomíticos aplicados em panelas de aço na produção de aços ao carbono. Brasil, Diss. Mestrado, Universidade Federal do Rio Grande do Sul, RS (2010) 4-12.

4 Steel Statistics Yearbook 2015 - World Steel Association, disponível em www.worldsteel.org (2015), acesso em: fevereiro de 2016.

5 BRASIL, Ministério de Minas e Energia - SGM, Relatório Técnico 71, Cadeia de refratários, projeto ESTAL, agosto de 2009. Disponível em: http://www.mme.gov.br/documents/1138775/1256652/P45_RT71_Perfil_dos_Refratxrio s.pdf/ac0e01f1-cc6d-4071-b3d4-c157240fa132, acesso em: abril de 2016.

6 BILGIÇ, M. Parameters effecting life time of refractory in steelmaking. Sweden: Department of Material Science and Engineering, 2005. 21 p.

7 MATTILA, R. A.; VATANEN, J. P.; HARKKI, J. J. Scandinavian J. Metallurgy 31 (2002) 241-245. 